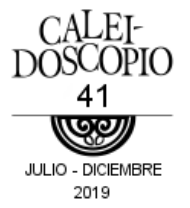

\title{
Los orígenes del Ferial de Aguascalientes
}

The origins of the Ferial of Aguascalientes

CARLOS REYES SAHAGÚN

Universidad Autónoma de Aguascalientes, México

\section{RESUMEN}

El Ferial de Aguascalientes es un espectáculo multidisciplinario que desde 1966 se presenta cada año, en el transcurso de la Feria Nacional de San Marcos, y que con el tiempo, y por derecho propio, se ha convertido en el principal evento artístico del Programa Cultural de la verbena. En este artículo se propone una reflexión en torno a los orígenes del espectáculo, ubicándolo en el contexto cultural en el que surgió.

Palabras clave: artes; promoción artística; caravana lírica.

\section{ABSTRACT}

The Ferial of Aguascalientes is a multidisciplinary show that since 1966 is presented every year, during the National Fair of San Marcos, and that over time, and in its own right, has become the main artistic event of the Cultural Program of the verbena. In this text I propose to reflect on the origins of the show, placing it in the cultural context in which it arose.

Keywords: arts; artistic promotion; lyrical caravan. 
A lo largo de su historia, el Ferial de Aguascalientes ha sido una expresión de las labores de educación artística que se han realizado, primero, en la Casa de la Cultura, y después en el Instituto Cultural de Aguascalientes (ICA); el gran espectáculo institucional, por lo menos en términos de producción, ha determinado la manera como se ha concebido y desarrollado, así como su origen. El siguiente testimonio confirma: "Ponía a trabajar a todo el mundo, porque era una expresión tanto de los bailarines como de los actores y de los músicos. Entonces, formaba parte de un trabajo que se estaba esperando, y que era entonces la expresión del Instituto Cultural, en el que participaban todos". En todo caso, habría que exceptuar de esta lista a los estudiantes de Artes Plásticas, por lo menos hasta 1990, dado que entre 1966 y 1989 el Ferial tuvo por escenario el segundo patio del Palacio de Gobierno, y careció de escenografía. Además, el Ferial ha sido el espectáculo oficial por excelencia; la culminación de la política cultural del Ejecutivo estatal. Prueba de ello es que aun cuando, salvo excepciones, los gobernadores del estado no han sido consumidores de arte $^{2}$-por lo menos no públicamente-, la cita anual para asistir al llamado Ferial oficial resultaba ineludible. ${ }^{3}$ Para explicar el origen del espectáculo hay que remontarse, en primer lugar, a agosto

\footnotetext{
${ }^{1}$ Mario García Navarro, director del Instituto Cultural de Aguascalientes, entre 1986 y 1990. Entrevista realizada por el autor el 17 de julio de 2015.

${ }^{2}$ Las excepciones serían, principalmente, Edmundo Games Orozco (1950-1953) y Otto Granados Roldán (1992-1998).

${ }^{3}$ Con el cambio de sede del espectáculo al Teatro de Aguascalientes y la introducción del cobro del boletaje, esta función oficial decayó como tal hasta desaparecer, aunque los gobernadores siguen asistiendo al espectáculo.
} 
de $1965^{4}$, cuando el poeta y teatrista Víctor Sandoval se hizo cargo del Instituto Aguascalentense de Bellas Artes (IABA) por invitación del gobernador Enrique Olivares Santana (1962-1968). Quien fuera también secretario particular del gobernador Luis Ortega Douglas (1956-1962), recordó: "estaba al frente del Instituto (Aguascalentense de Bellas Artes) un maestro muy querido, don Antonio Leal y Romero, pero sus mejores años habían pasado ya. Entonces, el profesor Olivares me dijo: hazte cargo del Instituto, y proponme algo más" ${ }^{n}$. Independientemente de ello, y de la trascendencia del nombramiento de Sandoval en el campo de la promoción artística, ya antes se habían realizado algunos esfuerzos dignos de consideración en materia de fomento de las artes y la cultura y de su difusión ${ }^{6}$, básicamente alrededor de los trabajos realizados por el Patronato de la Cultura, agrupación instaurada en diciembre de 1962, en el inicio de la Administración del gobernador Olivares. El organismo, instaurado por decisión gubernamental, pero integrado por personajes relevantes de la vida cultural del estado y empresarios, se habría planteado tres objetivos: la formación de un museo, la restauración del Teatro Morelos, y la fundación de una Casa de la Cultura. En cuanto a los dos primeros, estos objetivos se cumplieron en el transcurso de los primeros años.

\footnotetext{
${ }^{4}$ Julieta Rionda, La formación de la Casa de la Cultura de Aguascalientes 19451985. El proyecto en camino.

${ }^{5}$ Víctor Sandoval de León, fundador de la Casa de la Cultura de Aguascalientes; creador del Ferial de Aguascalientes. Entrevista realizada por el autor el 9 de octubre de 2009.

${ }^{6}$ Véase el trabajo de Salvador Camacho Sandoval, Bugambilias. 100 años de arte y cultura en Aguascalientes 1900-2000, que se refiere de manera detallada a los esfuerzos realizados en materia de fomento y difusión de las artes, antes de la fundación de la Casa de la Cultura de Aguascalientes.
} 
En octubre de 1964 el presidente Adolfo López Mateos realizó su gira de despedida por Aguascalientes ${ }^{7}$. Entonces, inauguró el Museo de la Insurgencia de Pabellón de Hidalgo, primer museo que tuvo Aguascalientes. Además, el Ejecutivo federal presidió la conmemoración del cincuentenario de la Convención de Aguascalientes, con lo que se inauguró la ansiada restauración del Teatro Morelos. A decir de Ladislao Juárez Ponce, la decisión por parte del gobernador Olivares de sustituir a Antonio Leal y Romero, tuvo su origen en una sugerencia de las autoridades del Instituto Nacional de Bellas Artes (INBA). Juárez Ponce, que a la llegada de Sandoval a la dirección del IABA se desempeñaba como coordinador artístico, recordó:

Las cosas estaban muy caídas. Yo le proponía algo: "oiga, don Antonio, ¿cómo ve si hacemos esto?, un coro", y él contestaba: "cuando usted sea director lo hará". "Oiga, ¿cómo ve si ponemos lo de folklórico? Cuando usted sea director lo hará". Nunca aceptaba nada; era muy miedoso para las promociones.

Montaba una obra de teatro de él, que duraban tres o cuatro meses ensayando, hacían vestuario; gastaban un dineral. La presentaban una sola vez, hacían una cena, y se acababa todo. Entonces, no tenía visión en ese aspecto.

Viene Bellas Artes y le dice al gobernador: "o cambia de director o nos retiramos de Aguascalientes". El profesor dijo: "¿a quién me proponen? Bueno, puede ser Víctor Sandoval. iHombre, me parece muy bien!", dijo8.

\footnotetext{
${ }^{7}$ López Mateos terminó su gestión el 30 de noviembre de ese año.

${ }^{8}$ Ladislao Juárez Ponce, compositor, creador del Ferial. Entrevista realizada por Jorge Campos Espino y el autor el 28 de abril de 2009.
} 
Probablemente esta afirmación de Juárez, en el sentido de que "las cosas estaban muy caídas", se aplique al IABA. Por lo tanto, hay que considerar que otra institución que a principios de los años sesenta realizaba labores artísticas en Aguascalientes era la Casa de la Juventud, del Instituto Mexicano de la Juventud Mexicana (INJUVE), que contaba con talleres artísticos, y que hacía importantes esfuerzos para arraigarse en la sociedad local. De hecho, algunos elementos, como la bailarina y coreógrafa María Elena Cardona Velasco, el bailarín y teatrista Jesús Velasco Velasco, el bailarín y coreógrafo José Luis Sustaita Luévano, y otros, comenzaron su trayectoria artística en esta institución, y luego pasaron al IABA. Además, el INJUVE propició que del nivel central auxiliaran de manera esporádica a la institución en Aguascalientes, para el desarrollo de actividades. Es el caso, por ejemplo, de Marcelo Torreblanca, que era también animador de misiones culturales, y un profesor de apellido Games: "Venían y nos daban cursos de semana; de dos semanas, y nos daban repertorio. Nos enseñaban danzas". Y en algunos casos, María Elena Cardona Velasco, por ejemplo, ya ejercía como docente en la Casa de la Juventud?. De regreso al tema de la llegada de Sandoval a la dirección del IABA, según Ladislao Juárez Ponce, al concluir la

9 José Luis Sustaita Luévano, bailarín, coreógrafo, director del Ferial de Aguascalientes en varias ocasiones. Entrevista realizada por el autor el 23 de marzo de 2017. Por su parte, María Elena Cardona Velasco informó que a Torreblanca, que fue toda una institución en materia de historia de la danza tradicional y de la investigación de estas prácticas populares. "Le gustaba mucho venir aquí a Aguascalientes y cada vez que venía iba a los baños de Ojocaliente, a los baños que les dicen de san Ramón. Entonces el maestro Sandoval aprovechaba las visitas de él como cada tres o seis meses y se estaba quince días, veintidós días o un mes y nos daba clase y nos daba algunas sugerencias, a mí me asesoraba para que siguiera trabajando con el grupo que estaba entonces en la Casa de la Juventud. Fue en el 60 o 59". María Elena Cardona Velasco, bailarina, coreógrafa. Entrevista realizada por Jorge Campos Espino y el autor, el 21 de julio de 2009. 
Administración del ingeniero Ortega, el nuevo gobernador, Enrique Olivares Santana, invitó a Sandoval a colaborar con él, sin embargo, no aceptó "porque fue muy leal al ingeniero Ortega. Hasta que terminara su gestión (en el Injuve) no quiso aceptar"10. En efecto, al terminar su encargo de la secretaría particular con el gobernador Ortega, Víctor Sandoval se incorporó al Injuve como coordinador de Casas de la Juventud". La obtención de este cargo se explicaría de la siguiente manera: en 1960 se construyó en Aguascalientes una de las primeras Casas de la Juventud del país. En su calidad de secretario particular del Ejecutivo estatal, es muy probable que Sandoval se hubiera relacionado con funcionarios del Injuve con el fin de cumplimentar los trámites que condujeron a la instalación de la Casa de la Juventud, y que, por cierto, incluyó la realización de una pintura mural llevada a cabo por un equipo, en el que figuró el chileno Oswaldo Barra C., que pintaría entre 1961 y 1963 los primeros murales del Palacio de Gobierno. Posiblemente esta circunstancia le habría permitido a Sandoval establecer relaciones que trascendieron la Administración de Ortega Douglas.

Víctor Sandoval permaneció en el Injuve hasta el 30 de noviembre de 1964, fecha en la que concluyó la Administración del presidente Adolfo López Mateos. En el transcurso de estos años, en la Administración federal, hizo "muchas amistades; muchas relaciones con Bellas Artes, y sobre todo con Sergio Galindo, Marco Antonio Montero; con toda la gente de Bellas Artes y lo proponen"12 para

\footnotetext{
${ }^{10}$ Ladislao Juárez Ponce, entrevista ya citada.

${ }^{11}$ Carlos Reyes Sahagún, Víctor Sandoval. El tiempo circular, tiempo de norias, Instituto Cultural de Aguascalientes, Colección Los Nuestros, Aguascalientes, 2013, p. 49 .

12 Ladislao Juárez Ponce, compositor, creador del Ferial de Aguascalientes. Entrevista ya citada.
} 
hacerse cargo del IABA. Por su parte, Jesús Eduardo Martín Jáuregui sostiene que en realidad el candidato inicial del gobernador Olivares para encabezar el IABA fue el médico y poeta Desiderio Macías Silva, y en todo caso éste habría declinado y recomendado a Sandoval como el más indicado para cumplir con este encargo ${ }^{13}$. En términos generales, se considera su gestión al frente de la institución artística como el inicio de la política cultural formal, definida, del estado de Aguascalientes, que articuló en un proyecto muy concreto la serie de actividades que se realizaban con anterioridad, tales como los Juegos Florales, la actividad de la Orquesta Sinfónica de Aguascalientes, y el propio IABA.

En el mediano y largo plazo, la nueva dinámica adquirida por la institución propició la fundación de Casas de Cultura municipales, museos, etc. Tan importante como lo anterior, e incluso más, el nuevo directivo buscó la importación de maestros que compartieran sus conocimientos con los educandos, y al mismo tiempo montaran espectáculos para el público local, de aquí que pueda afirmarse que su llegada a la institución artística constituyó "el gran momento fundacional de la política cultural estatal"1/4. En el momento de ser nombrado, Víctor Manuel Sandoval de León, nacido en 1929, contaba ya con una sólida trayectoria artística en Aguascalientes, fundamentalmente en el ámbito de las Letras, que lo haría

\footnotetext{
13 Jesús Eduardo Martín Jáuregui, entrevista realizada por el autor el 5 de diciembre de 2016. Sergio Rodríguez Prieto afirma que "Desiderio era la estrella que andaba por ahí, pero que no se involucraba". (Sergio Rodríguez Prieto, promotor cultural; colaborador fundador de XENM, Radio Casa de la Cultura y fundador de XEUAA, Radio Universidad. Entrevista realizada por el autor el 13 de noviembre de 2017).

${ }^{14}$ Eudoro Fonseca Yerena, profesor-investigador de la Universidad de las Artes del Instituto Cultural de Aguascalientes. Entrevista realizada por el autor el 7 de marzo de 2016.
} 
apropiado para el cargo, tal y como quedó de manifiesto en poco tiempo. Luis Mario Schneider escribió que Sandoval

cayó al incendio de la palabra a los 30 años. El viento de Norte (1959) inaugura una voz sin titubeos, atrevida. Osadía vanguardista con imágenes y metáforas equilibradas en una sed, en una armonía pertinaz de búsquedas. Es un docenario de poemas que recuerdan la sintaxis y las formas de aquel movimiento estridentista que provocó una ruptura en la literatura nacional. De paso, Víctor Sandoval compartió tertulias y amistad con Salvador Gallardo Dávalos, uno de los exponentes máximos del estridentismo. También El Viento Norte descubre esa tónica terca del futuro canto de Víctor Sandoval: fecundar en la tierra; su vinculación con la poesía cívica y la circunstancialidad amorosa llena de respiros, de esencia erótica.

Un año más tarde, Hombre de soledad (1960). Cinco sonetos donde el poeta, irritante y amatorio, se identifica con el ambiente campesino. Con ausencia de Dios, la llanura inmensa abraza y abrasa al hombre, lo envuelve en una tierna matriz para más tarde arrojarlo, libre y despechado, al mundo colectivo. Hálitos de espiga germinada, grano que se hará pan; penca nopalera y viento de horizontes, conductor de esfuerzos y experiencias. ${ }^{15}$

Precisamente el año en que Schneider ubica la aparición de El viento Norte, 1959, Sandoval había ganado la flor natural de los XXI Juegos Florales de la Feria de San Marcos de Aguascalientes con el poema "Hombre de

\footnotetext{
${ }^{15}$ Luis Mario Schneider, "Nota introductoria", en Víctor Sandoval, Colección Poesía Moderna, núm. 114, de Material de Lectura, (s.p.), Universidad Nacional Autónoma de México, México, 2011. Recuperado de http://www.materialdelectura .unam.mx/index.php/poesia-moderna/16-poesia-moderna-cat/265-114-victorsandoval?showall=\&start=1 [fecha de consulta: 31 de octubre de 2017].
} 
soledad $^{\prime \prime 6}$. Además, habría que señalar una efímera y discreta carrera teatral. Precisamente, hacia mediados de los años cincuenta Sandoval participó en el grupo de teatro de Antonio Leal y Romero, y en el que participaban también estudiantes de la Escuela Normal del Estado: "Me acuerdo que don Antonio Leal presentaba una obra de teatro con la Normal del Estado, y su grupo, porque en la Normal del Estado sólo había mujeres, y entonces él llevaba a los muchachos del IABA para participar como parte del reparto. Ahí conocí a mi mujer"17. Finalmente, también como parte de su trayectoria artística previa, hay que tener en cuenta el hecho de que hacia 1958 fungía como "coordinador artístico del IABA"18. A la par de estas actividades, también hay que recordar su participación en los dos principales grupos culturales que existieron en Aguascalientes en esos años, primero, la Asociación Cultural Aguascalentense (ACA), a principios de los años cincuenta del siglo anterior, y luego el Grupo Paralelo, a fines de esta década y principios de la siguiente, liderados ambos por el poeta estridentista de origen potosino Salvador Gallardo Dávalos, así como su paso por el Conservatorio Franz Liszt, una de las primeras instituciones que tenían por objetivo la promoción de las artes. Finalmente, a esto habría que sumar su trayectoria en el ya señalado Injuve, una institución que tuvo un gran protagonismo a fines de los años cincuenta y principios de los sesenta del siglo XX, y que en el caso de

${ }^{16}$ Ma. del Carmen Arellano Olivas y Martha Lilia Sandoval Cornejo, Los frutos ascendentes: Juegos Florales de la Feria de San Marcos, 1931-1967, Instituto Cultural de Aguascalientes, Aguascalientes, 2002, pp. 121-123.

${ }^{17}$ Víctor Sandoval de León, fundador de la Casa de la Cultura de Aguascalientes; creador del Ferial de Aguascalientes. Entrevista ya citada.

${ }^{18}$ Véase "Actuará en octubre junto con otros valores de B.A.", en El Heraldo de Aguascalientes, 25 de septiembre de 1958. 
Aguascalientes fue objeto de una serie de debates en torno a su orientación política y su papel en el adoctrinamiento juvenil.

Por cierto que fue gracias a la construcción de la Casa de la Juventud de Aguascalientes que el ya mencionado artista plástico chileno Oswaldo Barra estableció una relación con Aguascalientes que traería como consecuencia la realización de una serie de murales en los que Sandoval intervendría como informante del pintor, y luego como defensor de las obras y de su autor ante los ataques de algunos sectores de la sociedad ${ }^{19}$, principalmente de la prensa local. De regreso al nombramiento de Sandoval como director del IABA, de acuerdo con la noticia en la que se dio a conocer esta decisión gubernamental20 ${ }^{20}$ el poeta,

muy conocido en la población [...] expresó sus deseos por reorganizar totalmente los sistemas, en beneficio de los alumnos que cursan sus estudios en Bellas Artes [....

Víctor, debido a los viajes que ha efectuado por varias partes de la República, y en la Capital Azteca, ha obtenido experiencia en los aspectos culturales y artísticos, además de los cargos que ha desempeñado.

Finalmente, la nota también anunciaba que estaría a cargo de la Casa de la Cultura, en proceso de formación, en una dinámica que venía gestándose desde hacía varios

\footnotetext{
${ }^{19}$ Véase "Lección de historia patria ante el mural del segundo patio del Palacio de Gobierno de Aguascalientes, pintado por Oswaldo Barra en 1959", de Víctor Sandoval, en Poesía 1947-1999, Lecturas Mexicanas, Conaculta, México, 1999, pp. 14-19. En realidad, el mural al que se refiere en el poema fue pintado en 1961. Véase también Carlos Reyes Sahagún, op. cit., pp. 83 y siguientes.

${ }^{20}$ Véase "Víctor M. Sandoval, al frente del Instituto de Bellas Artes", en El Sol del Centro, 23 de agosto de 1965.
} 
años, y que sólo se concretaría de manera formal hasta 1967². De inmediato, Sandoval se dio a la tarea de reorganizar el IABA. En el corto plazo las decisiones tomadas trajeron como resultado el surgimiento de la Casa de la Cultura. En respuesta a lo solicitado por el gobernador Olivares,

yo le propuse la creación de una casa de la cultura. Yo tomé como base [... Han dicho que la primera Casa de la Cultura fue la de aquí, pero no, fue en Ecuador; en Quito, Ecuador. Luego vinieron las de Francia, que hizo André Malraux. Entonces, aquí, cuando se vino la cosa de crear la casa de cultura, lo primero que yo le plantee al profesor Olivares fue: "mire, hay una idea, de que la cultura es elitista. Yo creo que no es elitista; es cuestión de saber llevarla a todos los sectores, a quien según sus necesidades, a cada quien según su capacidad".

21 Aun cuando se asume que la creación de la Casa de la Cultura de Aguascalientes tuvo lugar en septiembre de 1967, poco más de dos años después del nombramiento de Sandoval, en el texto que da noticia del nombramiento del poeta como director del IABA, se informa que "el señor Sandoval también estará a cargo de la Dirección de la Casa de la Cultura". Véase "Víctor M. Sandoval, al frente del Instituto de Bellas Artes", en El Sol del Centro, 23 de agosto de 1965. Una lectura entre líneas de esta nota deja la impresión de que el IABA y la Casa de la Cultura eran entonces entidades diversas, en donde el primero resultaba ser una abstracción administrativa, y la segunda el edificio propiamente dicho, las instalaciones de aquél.

Independientemente de lo anterior, los planes para la creación de la Casa de la Cultura estaban en ese momento en su apogeo, y días antes de que Sandoval fuera nombrado director del IABA, se anunció que el Ejecutivo estatal adquiriría el edificio posterior al templo del Sagrario, y aledaño a la Escuela Tipo, a fin de integrarlo al proyecto de Casa de la Cultura. Véase "Una bella y poco conocida joya colonial será el edificio que albergue la Casa de la Cultura", en El Sol del Centro, 24 de julio de 1965.

Por otra parte, quizá no fuera ocioso señalar que en el programa de mano del Ferial de Aguascalientes correspondiente a 1969, es decir, casi tres años después de la fundación de la Casa de la Cultura, la producción del espectáculo es adjudicada al Instituto Aguascalentense de Bellas Artes. 
Entonces, le plantee la idea de crear una Casa de la Cultura, pero no de carácter elitista, sino para toda la gente $^{22}$.

Esta propuesta que Sandoval le hizo al gobernador, tendiente a revitalizar las actividades del IABA, en el corto plazo significaría la conversión del Instituto en Casa de la Cultura, y sería algo más que el cambio de edificio, que fue inaugurado el 15 de septiembre de $1967^{23}$, a pocos meses de que el profesor Enrique Olivares Santana culminara su gestión al frente del Ejecutivo estatal. No es este el espacio idóneo para referirse de manera pormenorizada a las metamorfosis de tipo académico que comenzaron a operarse con la introducción de los denominados talleres libres que, a su vez, redundaría en la formación de diversos grupos artísticos, pero baste señalar, para efectos de este artículo, que los cambios incluyeron, entre otras cosas, la transformación de los Juegos Florales en Premio de Poesía Aguascalientes y la creación del Encuentro Nacional de Estudiantes de Artes Plásticas y del Ferial de Aguascalientes, pensado este último como un espectáculo tendiente a despojar a la cultura de ese carácter elitista al que se hacía referencia. Por principio de cuentas, Sandoval en la dirección del IABA, y Juárez Ponce en la coordinación artística, comenzaron a trabajar con lo existente. Juárez Ponce recordó:

\footnotetext{
${ }^{22}$ Víctor Sandoval de León, fundador de la Casa de la Cultura de Aguascalientes; creador del Ferial de Aguascalientes. Entrevista ya citada. Ladislao Juárez Ponce consideraba que Víctor Sandoval "tenía esa capacidad de amansar y convencer políticos",véase Ladislao Juárez Ponce, compositor, creador del Ferial, entrevista ya citada.

${ }^{23}$ Véase "La Casa de la Cultura fue inaugurada ayer", en El Sol del Centro, 17 de septiembre de 1968.
} 
Empezamos a pensar: "Oye, ¿qué te parece si con los muchachos de guitarra, que estaban estudie y estudie y estudie y nunca tocaban, formamos una rondalla, para que apliquen sus conocimientos en las canciones y dominen la guitarra?", "¿Qué te parece si con los de canto hacemos un coro? Me parece bien; hazlo". "Oye, ¿qué te parece si el sexteto de cuerdas, hacerlo?". Entonces, él siempre me aceptaba todo ${ }^{24}$.

Por otra parte, y como ya se dijo, al mismo tiempo Sandoval aprovechó sus contactos en México, sus relaciones en Bellas Artes, para atraer maestros que enriquecieran y refrescaran la planta docente del Instituto ${ }^{25}$. Aquí es importante señalar que desde fines de los años sesenta y hasta mediados de los setenta, la planta docente experimentó un importante crecimiento. Una de las primeras adquisiciones fue la maestra Martha Díaz Cárdenas, que fue pionera en danza, dado que impartía clases de danza clásica, moderna y folclórica ${ }^{26}$, y que también se desempeñó como maestra de danza folclórica en la Escuela Normal del Estado ${ }^{27}$. Otros docentes que llegaron en la misma época fueron un maestro de teatro,

24 Ladislao Juárez Ponce, compositor, creador del Ferial de Aguascalientes. Entrevista realizada por Jorge Campos Espino y el autor el 28 de abril de 2009. Nótese la diferencia en la visión de Juárez Ponce, de las actitudes de Víctor Sandoval y Antonio Leal y Romero.

Al respecto, Érika Ortiz Juárez recordó, en función de la participación de los grupos en el Ferial, que había en la Casa de la Cultura danza clásica, folclor, flamenco, contemporáneo, teatro, taller literario, dos rondallas, un coro infantil, orquesta típica, orquesta de cámara, etcétera.

Érika Ortiz Juárez, cantante, violinista en la orquesta del Ferial; educadora, promotora cultural. Entrevista realizada por el autor el 31 de mayo de 2017.

${ }^{25}$ Carolina Castro Padilla, bailarina clásica, artista plástica, escritora. Entrevista realizada por el autor el 8 de marzo de 2017.

${ }^{26}$ Irene Clemente Sánchez, bailarina clásica. Entrevista realizada por el autor el 5 de diciembre de 2016.

${ }^{27}$ María Guadalupe Juárez Rodríguez, educadora, bailarina, maestra de danza. Entrevista realizada por el autor el 15 de noviembre de 2017. 
que venía de San Luis Potosí, Víctor Gándara; un maestro de guitarra, Ismael Guardado, y que estableció un taller libre de pintura ${ }^{28}$. Georges Berard llegó en 1969, y al año siguiente fundó el Ballet de Aguascalientes, aunque sus participaciones en el Ferial iniciaron hasta 1971, y permaneció a lo largo de 21 años ${ }^{29}$. El teatrista Jorge Galván llegó el mismo año, y de inmediato comenzó a participar en el Ferial, además de formar el grupo Teatristas de Aguascalientes, y con ello protagonizó una época de oro del teatro en Aguascalientes ${ }^{30}$. A propósito de esta efervescencia artística, Juárez Ponce recordó:

Cuando vimos, teníamos muchos grupos ya, que no podíamos sostener en cierto momento, es decir, vestuario, cuerdas, material. Entonces me dice: "¿qué te parece si hacemos un festival de fin de cursos [... En lugar de hacer un festival por cada grupo, juntamos todos los grupos y hacemos un festival para abril. La sinfónica anda muy mal, ya casi estaba muriéndose [...] No había jóvenes" ${ }^{\prime \prime 21}$. Entonces

\footnotetext{
${ }^{28}$ Pero también ocurrió lo contrario, y gracias a las gestiones de Sandoval, algunos estudiantes destacados fueron enviados a cursos de verano a México, para profundizar su formación. Fueron estos los casos de María Elena Cardona Velasco, Eduardo Games, Virginia Morales y José Luis Sustaita Luévano. María Elena Cardona Velasco, bailarina, coreógrafa. Entrevista realizada por Jorge Campos Espino y el autor, el 21 de julio de 2009.

${ }^{29}$ Carolina Castro Padilla. Entrevista ya citada

${ }^{30}$ En opinión de Sergio Rodríguez Prieto, personajes como el artista plástico Humberto Naranjo, Jorge Galván, Georges Berard, eran rebeldes que fueron ubicados en Aguascalientes "como castigo [...] Entonces, Aguascalientes se llenó de gente muy talentosa, que técnicamente le era conflictiva al sistema, pero que aquí se desarrolló a plenitud". Sergio Rodríguez Prieto, promotor cultural; colaborador fundador de XENM, Radio Casa de la Cultura y fundador de XEUAA, Radio Universidad. Entrevista realizada por el autor el 13 de noviembre de 2017.

${ }^{31}$ De hecho la orquesta fue disuelta por Víctor Sandoval en 1968. "Su decisión fue un duro golpe para todos, músicos y aguascalentenses [...] La explicación que se dio fue que no se contaba con los recursos suficientes para sostenerla". En Carolina Castro Padilla y Cecilia Franco Ruiz Esparza, El organista de Cristo José Ruiz Esparza Vega, Instituto Cultural de Aguascalientes, Ayuntamiento de Aguascalientes y Gobierno del Estado de Aguascalientes, Aguascalientes, 2007, p.
} 
le propuso al gobernador el festival [... y le pidió que a cambio de eso el Patronato de la Feria nos ayudara con vestuario $^{32}$, con el entarimado; con todos los gastos, y nos ayude también con los gastos de la Orquesta, que tienes que meter músicos extras. "De acuerdo", dijeron... El Ferial nació ahí, en Palacio de Gobierno ${ }^{33}$.

Por su parte, Sergio Rodríguez Prieto cree que la creación del Ferial fue una consecuencia, "hasta cierto punto natural", del desarrollo artístico que estaba viviendo Aguascalientes en general, y el IABA en particular; una manera de mostrar a la comunidad los resultados por todo lo que se hacía en la institución ${ }^{34}$. A decir de Víctor Sandoval, la idea del Ferial de Aguascalientes fue suya, en tanto que Ladislao Juárez Ponce se encargó de la música ${ }^{35}$.

44.

32 Por cierto que desde siempre el Ferial le ha ofrecido a la institución la oportunidad de proveerse del vestuario que se utilizaría a lo largo del año.

${ }^{33}$ Ladislao Juárez Ponce, compositor, creador del Ferial de Aguascalientes. Entrevista ya citada. Nótese la diferencia en la visión de Juárez Ponce, de las actitudes de Víctor Sandoval y Antonio Leal y Romero.

${ }^{34}$ Sergio Rodríguez Prieto, promotor cultural; colaborador fundador de XENM, Radio Casa de la Cultura y fundador de XEUAA, Radio Universidad. Entrevista realizada por el autor el 13 de noviembre de 2017. En concordancia con lo anterior, El Sol del Centro incluyó en su edición del 4 de mayo de 1967, una nota en la que se solicitaba que "EI Ferial de Bellas Artes debe ser llevado a los cuatro barrios de la ciudad, para que un mayor número de personas disfruten de él y conozcan el avance tan notable que ha logrado el Instituto Aguascalientense de Bellas Artes". Véase "Que lleven a los barrios la ferial (sic) de Bellas Artes", en El Sol del Centro, 4 de mayo de 1967.

${ }^{35}$ Ladislao Juárez Ponce consideró que en términos generales la idea del espectáculo fue de Sandoval, pero tocó a él estructurarla, darle la forma. "Qué hubiera hecho Víctor, por ejemplo, sin el apoyo de una persona, el caso mío, por ejemplo, que no le pidió dinero extra, que los arreglos yo los empecé a hacer, primero con música conocida, música popular. Después ya componiendo. No se hubiera realizado esto sin los maestros de danza, los maestros del coro, no hubieran puesto el entusiasmo que se puso". Ladislao Juárez Ponce, compositor, creador del Ferial. Entrevista ya citada. 
Yo le daba los textos; el guión [... Había un concierto, de la Orquesta Sinfónica de aquel entonces, a los invitados a la Feria de San Marcos, que lo presidía el gobernador. Y era un concierto en el que se tocaba a Mozart, etcétera, y bueno, ¿qué sentido era traer de México personalidades de la cultura, para que oyeran a un mal Mozart? No había condiciones para un concierto extraordinario. Entonces, cuando le plantee a Olivares, en lugar de ese concierto, para agasajar a sus invitados, entonces vamos haciendo, en el mismo lugar, en el mismo espacio, vamos haciendo mejor un espectáculo.

Me tenía mucha paciencia el gobernador, porque creían que iba a ser un espectáculo escolar.

"El Chato"36 no participaba antes. Participó conmigo. Lo jalé desde el principio, porque "El Chato" era maestro ahí, de piano, y lo jalé para que hiciéramos mancuerna; hicimos muy buena mancuerna. Yo ya había hecho este tipo de espectáculos en las Casas de la Juventud, no aquí, sino en otras, y aquí, cuando se inició la Casa de la Juventud, también hicimos un espectáculo para presentarlo allá, en el teatrito de la Casa de la Juventud. Participaron gentes que después se vinieron a la Casa de la Cultura. María Elena Cardona, que era bailarina, Jesús Velasco, y otros ${ }^{37}$.

Ladislao Juárez Ponce recordó que cuando Sandoval le hizo la propuesta al gobernador Oivares, ya ellos habían acordado encargarse de la organización.

\footnotetext{
${ }^{36}$ Este era el mote cariñoso con el que sus amigos se referían al compositor Ladislao Juárez Ponce.

${ }^{37}$ Víctor Sandoval de León, fundador de la Casa de la Cultura de Aguascalientes; creador del Ferial de Aguascalientes. Entrevista ya citada. La Casa de la Juventud de Aguascalientes fue inaugurada por el presidente Adolfo López Mateos en febrero de 1961, y se constituyó como una alternativa de capacitación para jóvenes, en ámbitos como el deporte, el civismo, el trabajo y la cultura, que abarcaba varias disciplinas artísticas.
} 
Este concierto al que hace referencia Sandoval, constituía el acto central del programa de actividades que se preparaba a los invitados del Ejecutivo estatal a la Feria de San Marcos, y que se conocieron con el nombre de Caravana Lírica.

Justamente, ante la expectativa de escuchar "un mal Mozart" -como afirmó Sandoval-, fue que se ideó la creación de un espectáculo que ofreciera a los invitados una muestra de lo que se hacía en Aguascalientes en materia de enseñanza artística.

$\mathrm{Si}$ bien es cierto que la Orquesta Sinfónica era la agrupación musical más importante del estado, como ya se señaló, distaba mucho de ser un conjunto profesional, entendido esto como la posibilidad de dedicarse de tiempo completo a esta labor, y que por eso mismo hubiera alcanzado un alto nivel de calidad.

Por principio de cuentas no era una agrupación permanente. Por el contrario, se integraba cuando debía realizar una presentación, los llamados conciertos reglamentarios que, por cierto, eran pocos a lo largo del año, para luego disolverse, y hasta la próxima ocasión.

Esta situación obedecía al hecho de que entonces la Orquesta Sinfónica constituía una mezcla de maestros de música y sus alumnos, y se encontraba en un proceso de declive que culminó con su desaparición, a fines de los años sesenta.

Se veía que había más buena voluntad que otra cosa. Recibían un estipendio, muy poco. Eran maestros de las orquestas típicas, músicos de las cantinas. Una parte de ellos, la cantina que tenía mi hermano, Cabo Cuarto, en la esquina de Allende y Cinco de Mayo [... Como cuatro o 
cinco músicos que estaban ahí; participaban en la Sinfónica ${ }^{38}$.

Otros ejecutantes obtenían su sustento en alguna de las orquestas que animaban las fiestas de Aguascalientes, en la Banda Municipal, o a través de la impartición de clases en alguna de las escuelas de la ciudad. Por ejemplo, Ricardo García Mendoza, miembro de una dinastía de personajes de mucha prosapia, dedicados al cultivo de la música, era también director de la Banda Municipal, en tanto que Ruiz Esparza se desempeñaba como organista titular de la Catedral y daba clases de piano.

A partir de lo anterior es posible afirmar que, en cierta medida, la Orquesta sobrevivía más por la decisión de sus miembros, por su voluntad de hacer música, que por los magros apoyos que recibía, la suscripción pública de boletos y algún apoyo gubernamental, incluyendo el préstamo del Teatro Morelos para sus presentaciones.

Muy lejos estaba todavía la formulación de una política pública que de manera muy puntual se pronunciara por el impulso de las artes, incluyendo a la Orquesta. Una prueba de las veleidades a las que estaba sometido el conjunto, se expresó en la nota que El Sol del Centro ofreció a sus lectores en su edición del 1 de mayo de 1948. En esa ocasión el diario informó lo siguiente:

Llegó a su fin la famosa Orquesta Sinfónica de Aguascalientes, cuando en días pasados todos sus componentes se congregaron en uno de los portales del parián y en plena vía pública expresaron su descontento porque no les han sido cubiertos sus sueldos correspondientes a dos meses atrasados.

\footnotetext{
${ }^{38}$ Víctor Sandoval de León, fundador de la Casa de la Cultura de Aguascalientes; creador del Ferial de Aguascalientes. Entrevista ya citada.
} 
El periódico agregó que los integrantes del conjunto eran artistas pobres que solamente cobraban 30 pesos mensuales, insuficientes para sostenerse. Además, algunas personas lamentaron que ni el gobierno, ni las asociaciones ni al menos una empresa, se interesasen en esta obra "que sin vanidades, estaba recibiendo ya los frutos maduros de sus triunfos", dado que ya comenzaba a hablarse de ella como la segunda del país. Pero en rigor este era más un buen deseo que la aseveración de un hecho real, y la Orquesta distaba de contar con la calidad que podía encontrarse en otros conjuntos.

Vale la pena detenerse un instante en la mencionada Caravana Lírica, porque constituye el antecedente más inmediato del Ferial de Aguascalientes.

A decir de Víctor Sandoval, esta Caravana Lírica fue una creación del profesor Alejandro Topete del Valle, a la sazón "Cronista de la Ciudad"39, y la organizaba juntamente con el Círculo de Aguascalentenses en México. En la época en que fue gobernador del estado el ingeniero Jesús $M$. Rodríguez Flores, "El Chapo", la Caravana tomó el gran impulso que la caracterizó hasta prácticamente su disolución, en los años sesenta.

Por principio de cuentas es importante destacar el gran impulso que la Feria de San Marcos le ha dado al desarrollo de las artes, que en cierta medida se explica por el deseo de los organizadores de otorgarle a la verbena

\footnotetext{
${ }^{39}$ Víctor Sandoval de León, fundador de la Casa de la Cultura de Aguascalientes; creador del Ferial de Aguascalientes. Entrevista ya citada. Aunque ciertamente ya antes se contó con personajes procedentes de la capital del país en la velada de los Juegos Florales, que venían realizándose desde 1931 y que fueron, con mucho, el principal acontecimiento artístico de la Feria de San Marcos. Probablemente haya sido el profesor Alejandro Topete del Valle, que ya para entonces era un personaje relevante, quien impulsó a la Caravana Lírica en sus primeros tiempos. Sin embargo, es preciso aclarar que Topete se convertiría en "Cronista de la Ciudad" hasta mediados de la década de los cuarenta.
} 
sanmarqueña un contraste civilizatorio con prácticas tan arraigadas y propias de una feria como lo son el juego, el consumo de alcohol, etcétera ${ }^{40}$. Por otra parte, tradicionalmente las también conocidas "Fiestas de abril" han sido asumidas como una oportunidad de desarrollo para la economía local, básicamente para los prestadores de servicios y los comerciantes.

Por lo anterior es posible afirmar que ciertamente la Feria ha sido para propios y extraños, pero tradicionalmente sus organizadores han realizado un intenso trabajo de promoción que ha buscado captar más bien a la gente de otras ciudades, convencerla de los avances que experimenta el estado y atraerla al disfrute de los festejos abrileños, con la consiguiente derrama económica que esto significa.

En esta dimensión, es preciso tener en cuenta la participación de los dirigentes del Patronato de la Feria, y de la reina y sus princesas, en programas de radio y televisión nacionales.

Una actividad que se inscribe en esta dinámica de promoción externa, y que se realizó durante varios años, fue el programa de radio "Así es mi tierra", que formó parte de lo que hacia la década de los años cincuenta comenzó a llamarse Teatro del Pueblo, hoy Foro de las Estrellas.

Patrocinado por la compañía vinícola de Coahuila, Casa Madero, por lo menos en una ocasión, en tiempo de la Feria de San Marcos el programa se transmitía en directo desde el Jardín de San Marcos, o desde algún otro espacio típico. En él participaban artistas de fama nacional, que

\footnotetext{
40 Este tema ha sido ampliamente trabajado por Jesús Gómez Serrano. Ver Mercaderes, artesanos y toreros: la Feria de Aguascalientes en el siglo XIX, Instituto Cultural de Aguascalientes, Gobierno del Estado de Aguascalientes, México, 1985, e Historia de la Feria Nacional de San Marcos 1828-2006, Gobierno del Estado de Aguascalientes, México, 2007.
} 
cultivaban la canción vernácula, como Tito Guizar, José Alfredo Jiménez, Ignacio Fernández Esperón "Tata Nacho", Avelina Landín, etcétera.

Probablemente en la década de los treinta del siglo XX, pero ya de manera documentada en la década siguiente, principalmente en El Sol del Centro, el Ejecutivo estatal comenzó a invitar a la Feria a personajes relevantes de la capital del país, que tenían algún cargo en el gobierno federal, y/o que formaban parte del mundo artístico: escritores, artistas plásticos, músicos y cantantes, muchos de ellos miembros del entonces flamante Seminario de Cultura Mexicana.

De esta forma, se convirtieron en asiduos de la verbena abrileña personajes de la talla de Artemio de Valle Arizpe, Renato Leduc, Antonio Acevedo Escobedo, etcétera.

A éstos se sumaban personajes destacados de la colonia aguascalentense en el DF, un organismo de personas originarias del estado que habían migrado desde el terruño a la capital, que tuvo una gran resonancia hacia mediados del siglo XX.

Precisamente fueron estas celebridades quienes integraron lo que se conoció como la Caravana Lírica.

Estos personajes, algunos de ellos relacionados con medios de comunicación nacionales, cumplían además algunas funciones más allá del programa preparado por el Ejecutivo estatal en colaboración con las fuerzas vivas, la asistencia a los toros, los tapancos, etcétera. Fungían, por ejemplo, como jurados en los Juegos Florales, o mantenedores de los mismos y participaban en la ceremonia de entrega de premios, que en esos años revestía la mayor solemnidad.

Hacían acto de presencia en Aguascalientes, y permanecían en la ciudad tres o cuatro días, a fin de participar en los festejos. Eran agasajados por el siempre 
festivo y dinámico Club Rotario, asistían a los toros, a la verbena que se organizaba en su honor en la Huerta Games $^{41}$, una actividad típicamente pueblerina en la que, como si se tratara de un día de campo, se degustaban los llamados antojitos mexicanos, acompañados por aguas frescas de frutas y tequila, y música de orquesta típica y mariachi.

También daban entrevistas a los medios de comunicación locales, principalmente El Sol del Centro, y algunos de ellos escribían luego sobre la fiesta, o tal vez aprovechaban alguna oportunidad para hablar bien de sus anfitriones como, por ejemplo, Guillermo Castillo, "Júbilo", que en 1941 escribió que la Caravana Lírica era una institución integrada por poetas, escritores, periodistas, pintores, dibujantes, etcétera, (que) rindió el homenaje de su admiración, siempre abierta a los valores de la provincia, a Aguascalientes ${ }^{42}$.

Uno de los actos centrales de esta promoción; de esta hospitalidad a los personajes ilustres de la Caravana Lírica, era un evento artístico que ofrecía la Orquesta Sinfónica, y que tenía lugar en el Palacio de Gobierno, al medio día de una de las jornadas cercanas al 25 de abril, al que se invitaba también a quienes encabezaban a las fuerzas vivas del estado, empresarios, miembros de clubes de servicio, etc.

En términos generales, para los invitados del Ejecutivo estatal, procedentes de la ciudad de México, con una visión más amplia e ilustrada, el concierto de referencia quizá no fuera la mejor opción, dados los antecedentes señalados. Esto porque vivir en la capital ofrecía un amplio

\footnotetext{
${ }^{41}$ Hoy el Parque Hidalgo.

42 Guillermo Castillo, "Júbilo", "Hacia la Feria de San Marcos", en El Universal Gráfico, 3 de mayo de 1941. Véase Antonio Acevedo Escobedo, Letras sobre Aguascalientes, México, 1963, p. 156.
} 
espectro de posibilidades artísticas que no existían en Aguascalientes: asistir a los conciertos de la Orquesta Sinfónica Nacional, este sí un conjunto profesional, en ocasiones con solistas de talla internacional, o a recitales de conjuntos de cámara, de piano, o participar de la vida artística que animaba al Conservatorio Nacional de Música, etc.

Cortesías aparte, probablemente los invitados a este concierto ferial llegaran a la conclusión de que escuchaban a un conjunto de menor calidad a los que podía encontrarse en México.

Entonces se tuvo la idea de ofrecerles algo diferente a lo que podían encontrar en su lugar de residencia, y que por sus características ofreciera ese sabor local que gustan de buscar quienes viven en las grandes urbes y se atreven a mirar allende Cuautitlán, quizá porque les diera la sensación de un origen perdido; de un tiempo y lugar que ya no son los suyos.

Esta idea alcanzó su concreción en 1966, con la realización del Ferial de Aguascalientes, que contaría con la participación de los alumnos de las distintas disciplinas que se impartían en el IABA.

La Caravana Lírica terminó hacia mediados de los años sesenta, debido a las trasformaciones que vivió la Feria de San Marcos en su dimensión artística. Algunos factores principales que influyeron en contra de este movimiento fueron los siguientes: en primer lugar, "llegó un momento en que ya no tenía sentido, porque se iban muriendo las gentes que estaban en México"43. En segundo lugar, los actos centrales que animaban a la Caravana Lírica, se transformaron de manera radical. Fue el caso del concierto

\footnotetext{
${ }^{43}$ Víctor Sandoval de León, fundador de la Casa de la Cultura de Aguascalientes; creador del Ferial de Aguascalientes. Entrevista ya citada.
} 
señalado, que se convirtió en el Ferial de Aguascalientes y, sobre todo, los Juegos Florales y su rancio ceremonial de entrega, que vivieron su última edición en 1967, y desaparecieron para dar paso, a partir del año siguiente, al Premio de Poesía Aguascalientes.

Habría que señalar que en 1968 comenzó el Programa Cultural, conformado a partir del talento local, además de algunos eventos procedentes del Festival Internacional Cervantino, que en sus primeras ediciones se realizaba en abril y mayo. Ciertamente, antes de que existiera el Programa Cultural, había unas pocas actividades artísticas, primordialmente la velada de los Juegos Florales, que eran desarrolladas por personajes que integraban la Caravana Lírica y que terminó volviéndose anacrónica hasta desaparecer.

A manera de conclusión, podría afirmarse que el Ferial tuvo un triple origen; tres factores que convergieron en la realización del espectáculo que conocemos como Ferial de Aguascalientes. En primer lugar, el nombramiento, en agosto de 1965, del poeta y teatrista Víctor Sandoval para encabezar el Instituto Aguascalentense de Bellas Artes, y luego la Casa de la Cultura, en un hecho que significó una profunda renovación de la institución gubernamental encargada de la promoción y difusión de las artes.

En segundo lugar estaría la dinámica artística que estaba desarrollándose en Aguascalientes en esos años, y que encontró en el Ferial y en otros espectáculos un cauce natural de salida.

Finalmente, no hay que olvidar el hecho de que el Ferial fue ideado en un primer momento como un buen sustituto del concierto que el Ejecutivo estatal ofrecía a sus invitados en la Feria Nacional de San Marcos, la llamada Caravana Lírica, la cual se desarrolló a la par de los Juegos Florales, y que pronto adquirió lo que podría denominarse 
como una carta de ciudadanía, gracias a la fama de quienes la integraron, artistas de las Letras y la música principalmente.

\section{REFERENCIAS}

Arellano Olivas, Ma. Del Carmen, y Sandoval Cornejo Martha Lilia, Los frutos ascendentes: Juegos Florales de la Feria de San Marcos, 1931-1967, Instituto Cultural de Aguascalientes, Aguascalientes, 1ª. Ed, 2002.

Camacho Sandoval, Salvador, "Bugambilias, 100 años de arte y cultura en Aguascalientes", 1900 2000. Universidad Autónoma de Aguascalientes, Consejo Estatal de Ciencia y Tecnología e Instituto Cultural de Aguascalientes, Aguascalientes, Ags., $1^{\underline{a}}$ ed. 2010. Castillo, Guillermo, "Hacia la Feria de San Marcos", en Antonio Acevedo Escobedo, Letras sobre Aguascalientes, Gobierno del Estado, 1ª . Ed. 1963.

Castro Padilla Carolina, y Franco Ruiz Esparza Cecilia, El organista de Cristo José Ruiz Esparza Vega, Instituto Cultural de Aguascalientes, Ayuntamiento de Aguascalientes y Gobierno del Estado de Aguascalientes, Aguascalientes, 1‥ Ed. 2007 Gómez Serrano, Jesús, Historia de la Feria Nacional de San Marcos 1828-2006, Gobierno del Estado de Aguascalientes, México, 1‥ Ed, 2007.

Gómez Serrano, Jesús, Mercaderes, artesanos y toreros: la Feria de Aguascalientes en el siglo XIX, Instituto Cultural de Aguascalientes, Gobierno del Estado de Aguascalientes, México, $1^{a}$. Ed. 1985.

Reyes Sahagún, Carlos, "Víctor Sandoval. El tiempo circular, tiempo de norias", Instituto Cultural de Aguascalientes, Colección Los Nuestros, 1ª Ed. 2013. 
Rionda, Julieta, "La formación de la Casa de la Cultura de Aguascalientes 1945-1985". Inédito.

Sandoval, Víctor, "Lección de historia patria ante el mural del segundo patio del Palacio de Gobierno de Aguascalientes, pintado por Oswaldo Barra en 1959", de Víctor Sandoval, en Poesía 1947-1999, Lecturas Mexicanas, Conaculta, México, 1999

Schneider, Luis Mario, "Nota introductoria", en Víctor Sandoval, Colección Poesía Moderna, núm. 114, de Material de Lectura, (s.p.), Universidad Nacional Autónoma de México, México, 2011. Recuperado de http://www.materialdelectura.unam.mx/index.php/poesi a-moderna/16-poesia-moderna-cat/265-114-victorsandoval? showall=\&start=1 (fecha de consulta: 31 de octubre de 2017).

\section{ENTREVISTAS}

María Elena Cardona Velasco, entrevista realizada con Jorge Campos Espino el 28 de abril de 2009.

Carolina Castro Padilla, entrevista realizada el 8 de marzo de 2017.

Irene Clemente Sánchez, entrevista realizada el 5 de diciembre de 2016.

Eudoro Fonseca Yerena, entrevista realizada el 7 de marzo de 2016.

Mario García Navarro, entrevista realizada el 17 de julio de 2015.

Ladislao Juárez Ponce, entrevista realizada el 28 de abril de 2009.

María Guadalupe Juárez Rodríguez, entrevista realizada el 15 de noviembre de 2017. 
Jesús Eduardo Martín Jáuregui, entrevista realizada el 5 de diciembre de 2017.

Erika Ortiz Juárez, entrevista realizada el 8 de marzo de 2017.

Sergio Rodríguez Prieto, entrevista realizada el 13 de noviembre de 2017.

Víctor Manuel Sandoval de León, entrevista realizada el 9 de octubre de 2009.

José Luis Sustaita Luévano, entrevista realizada el 23 de marzo de 2017.

\section{ACERCA DEL AUTOR}

Carlos Reyes Sahagún (careyes@correo.uaa.mx) es Licenciado en Ciencia Política por la Universidad Autónoma Metropolitana. Además cuenta con una maestría en Investigaciones Sociales y Humanísticas por la Universidad Autónoma de Aguascalientes, institución en la que se desempeña como profesor e investigador de tiempo completo, en el departamento de Historia del Centro de Ciencias Sociales. Ahí ha impartido diversas materias relacionadas con la Historia de México y la Historia del Arte.

Recibido: 26/08/2018

Aceptado: 22/10/2018 
CÓMO CITAR ESTE ARTÍCULO

Reyes Sahagún, C. (2019). Los orígenes del Ferial de Aguascalientes. Caleidoscopio - Revista Semestral de Ciencias

Sociales y Humanidades, 23(41), 25-52. doi:10.33064/41crscsh1325

52 NÚM. 41 JULIO - DICIEMBRE 2019 doi:10.33064/41 crscsh1325 